times lacking this weekend. Psychiatric syllabuses and teaching, and of course the Membership examination, are all orientated towards diagnosis. The formulation, explicit or implicit, is always a prerequisite to any choice of treatment, plan of management, or prediction of who will do well. Diagnostic formulation is the number one way in which psychiatrists, by target, by training and experience, differ from nurses, social workers and other so-called caring professionals, and the curious thing is the conference barely mentioned it.

To be critical does not mean one is ungrateful for all the hard work which goes into mounting such a meeting. Part of its value lies in the stimulatory effect of the pre-Conference working parties, part in the opportunities for informal social contacts in beautiful and unusual surroundings, with a very high standard of eating and drinking. And of course this Conference is not the finish, but just another step towards adapting practice to need.

\title{
Report on the Conference on Tasks and Problems for Peripatetic Trainees in Psychotherapy
}

\author{
JoHN SkLaR, Senior Registrar in Psychotherapy, The Tavistock Clinic
}

The one-day conference, organized by the Psychotherapy Advisory Sub-Committee of the Joint Committee in Higher Psychiatric Training took place on 8 October 1981 under the chairmanship of $\mathrm{Dr} \mathrm{H}$. Wolff, at the Institute of Psychoanalysis.

The Conference took off with Dr Tom Main's account of his group of doctors practising in sexual clinics in Newcastle which he supervises weekly by telephone. He insisted that psychotherapeutic skills cannot be divorced from the setting in which they are used.

Dr Malcolm Pines gave an account of a two-year course by the Institute of Group Analysis in Denmark. Though initially aimed at teaching supervision, it had become a training in basic psychodynamic principles.

Dr Colin James followed on by talking about his five-year training course in group psychotherapy, also in Denmark. He felt that the adaptation to the setting must in no way interfere with the task of teaching psychoanalytic theory and technique.

Dr John Cobb brought the conference back to Britain by describing his peripatetic training in the South West Thames Region. Covering 200,000 miles in two years, he endeavours to teach 'the psychotherapies' using a variety of techniques. He enounters many problems, highlighted by the basic lack of interpersonal skills in our medical profession.

Dr John Evans was the last trainer to speak. He took the view that consultants in psychotherapy should have an 'indepth training' as provided by the Scottish Institute of Human Relations or the Institute of Psycho-analysis.

The participants were then divided into four groups each including a member of the Psychotherapy Advisory SubCommittee.

In the afternoon four trainees were invited to speak. The first. Dr P. Whewell, described his life as a senior registrar in Newcastle training at the Scottish Institute of Human
Relations in Edinburgh, and the effort involved.

Dr Klar, from York, followed with an enthusiastic account of his training in behaviour therapy at the Institute of Psychiatry.

Dr Somekh, a senior registrar in general psychiatry at the Maudsley Hospital and a trainee at the Institute of Psychoanalysis. described the polarization in his hospital between general psychiatrists and psychotherapists and commented on the negative attitudes towards psychoanalytic training which seemed to be held by some senior staff at his hospital, despite the College's approval of the Institute training as a valuable component of the senior registrar's training in psychotherapy.

Dr Jane Price from Nottingham was the only trainee to speak who relied purely on local resources for her training. She stressed the need for trainers to actually experience the context in which their trainees work and the need to adapt their method to these settings. She emphasized the need for specialized training in both supervision work and in family therapy.

The plenary discussion took place after a second meeting of the small groups. It was unfortunate that some of the familiar polarization of 'those who have and those who have not' in relation to training facilities was not directed more to practical issues such as attracting London-based trainers to undertake short courses and supervision for the provinces, as it seems that there is more fluidity today.

More familiar issues such as research problems in psychotherapy were aired, as well as the interesting theme of 'psychic pain'. This latter being a point in discovering the amount of psychological depth that the clinician feels comfortable in his approach to his patient.

The dialogues continue and it is hoped that this meeting will become an annual event. 